\title{
Re: Thyroid incidentalomas in FDG-PET/CT: prevalence and clinical impact
}

\author{
Brendan C. Stack Jr • Donald L. Bodenner • \\ Twyla B. Bartel · Jacob Boeckmann
}

Published online: 6 March 2012

(C) Springer-Verlag 2012

\section{Dear Editor,}

We read Dr. Bonabi et. al [1] article with great interest as we have pursued this topic in our center over the years [2-4]. We practice at a busy international multiple myeloma referral center so we have a busy nuclear medicine/ PET practice with abundant PET data. We agree with the authors that incidental focal thyroid lesions on PET CT should be taken seriously. They should be pursued as any thyroid nodule is, when encountered clinically or incidentally, by ultrasound directed fine needle aspiration biopsy and further expectant management based on cytology.

Diffuse thyroid uptake on PET/CT is not a concern for malignancy and is indicative of thyroid disease which may ultimately require medical management [2].

With regards to focal thyroid uptake on PET/CT, our group has come to some slightly different conclusions regarding interpretation of the PET data [3]. In our recent study, 23,384 PET and PET/CT scans performed between December 2001 and April 2011 were reviewed. Incidental thyroid uptake was noted in 1,309 PET scans (5.17\%), focal uptake in $690(2.95 \%)$ and diffuse uptake in 619 (2.64\%). Malignancy was identified in $27 \%$ of patients with focal uptake, $89 \%$ of which were primary thyroid malignancies. A significant difference between malignant $\mathrm{SUV}_{\max }$ and benign $\mathrm{SUV}_{\max }$ was found (mean $\pm \mathrm{SD}=$ $7.04 \pm 7.88$ for malignancies vs. $3.85 \pm 3.06$ for benign tumors, $P=0.0292$ ). Receiver operating characteristics

B. C. Stack Jr ( $₫)$ · D. L. Bodenner · T. B. Bartel .

J. Boeckmann

Departments of Otolaryngology-Head and Neck Surgery,

Geriatrics and Radiology, UAMS Thyroid Center,

University of Arkansas for Medical Sciences,

Little Rock, AR, USA

e-mail: BStack@uams.edu curves (ROC) were constructed on patients with PET data within 3 months of diagnosis, and indicated that a SUV $\max$ of 4.2 differentiated maximally between benign and malignant lesions. Serial SUV uptake measurements of thyroid lesions obtained incidentally for other oncologic surveillance had no significant change over time.

Incidental focal thyroid uptake on PET/CT has the most clinical significance for possible malignancy of any other type of thyroid "incidentalomas" detected by other imaging modalities (CT, MR. U/S). These lesions should be approached according to best practices as recommended by current guidelines on thyroid nodule evaluation.

Sincerely,

Brendan C. Stack Jr, MD, FACS, FACE

Donald L. Bodenner, MD, PhD.

Twyla B. Bartel, DO, MBA

Jacob Boeckmann, MD

\section{References}

1. Bonabi S, Schmidt F, Broglie MA, Haile SR, Stoeckli S (2012) Thyroid incidentalomas in FDG-PET/CT: prevalence and clinical impact. Eur Arch Oto-Rhino-Laryngol 2012 (Epub ahead of print)

2. King D, Stack BC Jr, Spring P, Walker R, Bodenner D (2007) Thyroid carcinoma in fluorodeoxyglucose whole body positron emission tomography (PET) positive thyroid "incidentalomas". Otolaryngol Head Neck Surg 137(3):400-404

3. Rothman IN, Middleton L, Stack BC Jr, Riggs AT, Bartel TB, Bodenner DL (2011) The incidence of diffuse fluorodeoxyglucose positron emission tomography (PET) uptake in the thyroid of patients with autoimmune thyroiditis. Eur Arch Otolaryngol 268(10):1501-1504 (Feb 16 epub)

4. Boeckmann J, Siegel E, Bartel T, Bodenner D, Stack BC Jr (2012) Can pathology of a thyroid nodule be determined by PET? Otolaryngol Head Neck Surg (epub Feb 3) 